\title{
Corporate Governance and Debt Management of Vietnam's SMEs
}

\author{
Pham Thu Ha, Nguyen Tien Phong \\ Hanoi University of Technology, Hanoi, Vietnam
}

\begin{abstract}
The paper aims to examine the relationship between corporate governance and debt management of Vietnam's small and medium enterprises (SMEs), in a case study of a specific enterprise. It reveals one case that corporate governance factors have strong correlation with performance, due to transparency to the lender, innovative and consistent to the debt management. The results indicate that timely reporting and level of disclosure positively affect corporate performance and ability to raise funds in the financial market. The paper seeds new light into the relationship between corporate governance and debt management of Vietnam's SMEs in current context. It finds ways to solve financial dilemma and raise corporate equity value that most SMEs are facing.
\end{abstract}

Keywords: corporate governance, renovation, transparency, debt management, small and medium enterprises (SMEs), debt restructuring

\section{Introduction}

Like people, a healthy company sometimes falls ill because of health management. If correct treatment is introduced, the company can recover and continue to grow; otherwise, it will go bankrupt sooner or later. For effective treatment, it is, first of all, necessary to analyze its illness in a very objective manner.

Such analysis often requires studies or the expertise of a banker, financial analyst, or experienced savior who is independent of the company, so they can see the problem clearly. Main questions usually include:

(1) Is the company's illness caused by a general decline of the economy or some industry or is it just a temporary problem specific to the company itself?

(2) What are the possible causes of the problem?

(3) What are the possibilities of saving the company?

In order to answer the first question, the company's current situation must be analyzed. One of the major methods is to take a look at the company's financial ratios over the past few years and if possible, compare them with those of other companies in the same line of business. This is a relatively complex issue that cannot be presented fully within this article.

After finding the company's weaknesses by looking at its financial situation, the next thing to do is to

Pham Thu Ha, Ph.D., assistant professor, Industrial Economics Department, Economics and Management Institute, Hanoi University of Technology, Hanoi, Vietnam.

Nguyen Tien Phong, Ph.D., lecturer, Industrial Economics Department, Economics and Management Institute, Hanoi University of Technology, Hanoi, Vietnam.

Correspondence concerning this article should be addressed to Nguyen Tien Phong, Office 206b, Building C9, Hanoi University of Technology, 1 Dai Co Viet Street, Hanoi, Vietnam. E-mail: phong.nguyentien@hust.edu.vn. 
identify the causes of such weaknesses. The causes can be listed as "internal" or "external" and as happening "once" or "repeatedly" as is shown in the following Table 1.

Table 1

Cause of Such Weaknesses

\begin{tabular}{|l|l|l|}
\hline & Internal causes & External causes \\
\hline Happening once & A large project failed & The prices of input materials suddenly increased \\
\hline & The company failed to move to another line of business & Laws suddenly changed \\
\hline Happening repeatedly & The company's monitoring system was inefficient & There were new production techniques \\
\hline & Production costs increased & Imported goods were competitively cheap \\
\hline
\end{tabular}

The above example shows that the lower people move in the table, the problem becomes more difficult to solve and the further right people move, the more difficult it is to save the company.

Companies in difficult situations normally blame external factors. However, it is their management which has to be responsible, because they fail to foresee external changes so as to introduce countermeasures. A driver, who, despite seeing dark clouds signaling a coming storm, accelerates his way into the rain and wind instead of pulling over, cannot blame anyone else, should he crash.

Normally, ailing companies are faced with problems listed in the bottom left corner. They may still manage to survive for a while, but when external factors take their tolls, they will not be able to withstand them and will finally collapse. According to international statistics, among bankrupt companies, only $10 \%$ fail, because of extreme external factors. Half of those who fail because of external factors could have been saved, if their management had been more capable. The remaining $40 \%$ fail because of internal problems: corporate governance. In other words, management is responsible for $90 \%$ of a company's survival. Internal management can be categorized as follows.

\section{Repeated Causes}

(1) Poor general management is as follow (Han, 1992a):

a. Managements have been idle for so long, they fail to respond effectively to outside changes caused by competition or changes in customers' taste;

b. A person normally takes several years to master a professional technique. A general director, however smart he may be and no matter what experience he has with his previous field, cannot learn it in a short period of time;

c. A successful company may decline, because it is too rigid to change its strategies or ways of working in response to new market circumstances;

d. Many companies, especially those in manufacturing, fail because their managements are only technically capable but are short of financial or sales expertise;

e. Difficulty-stricken companies normally do not have a clear-cut common path. Each of its divisions takes a different path.

(2) Poor general management is as follow:

a. The company does not know how to control or forecast its cash flow;

b. It lacks a system for analyzing profits and losses and one for calculating product costs and therefore management cannot take a right decision;

c. The company is bad at controlling its budget; 
d. It has all the above systems or capabilities but does not know how to use them properly.

(3) Poor general management is as follow:

a. Management and production costs are too high;

b. Marketing is inefficient and fails to spot latest changes in the market. It does not have new tactics, programs of action or products to cope with new competition.

\section{Causes That Happen Once}

(1) Engaging the company in an enormous project is one of the causes.

Many companies which are running smoothly suddenly go bankrupt, because they are involved in a project too large for them. Such projects normally have one or more than one of the following characteristics:

a. They are $25 \%$ larger than the companies' existing assets;

b. They involve technologies too new for the companies.

(2) Engaging the company in completely unfamiliar trades is another one.

The question "what are the possibilities of saving the company?" is relatively difficult to answer, because such possibilities depend on various factors and circumstances. Some treatment can be effective abroad, but may not be applicable in Vietnam. Take "turning debts into capital" or "reducing debts" which debtors or banks often do in order to save companies for instance.

Generally speaking, experience in capitalist economic systems shows that, except for cases of deliberate cheating or complete loss of assets, it is possible to save a badly managed company and help it recover, if its illness is detected early and treated correctly (Han, 2010).

\section{The Case of the Canadeo Hotel}

During the housing and estate crisis in Vietnam in 2010 to 2013, one of the above-mentioned reasons (poor financial management and the company does not know how to control or forecast its cash flow) was responsible for the collapse of many small and medium enterprises (SMEs), including those owning the Canadeo Hotel in Hanoi. Those SMEs used short-term loans to sponsor a long-term project: the Canadeo Hotel.

That was a very common type of bank loans at the time. Basically, it would be provided for a period of three years or eight years. The SMEs at Vietnam could use it to build a beach resort (usually in Da Nang or Nha Trang) or build the project of hotel in the big town. In this case, the investors of Canadeo Hotel invested 600 billion (VND) on the project 100-rooms. They already had 200 billions, so they borrowed the remaining 400 billions from Seabank for a period of eight years. In the first five years, they would only have to pay the interest. After that, at year end, they would have to pay the interest and 100 billion worth of the principal.

It was a major mistake in managing cash flow. In the first five years, they earned enough from the hotel and their other businesses to pay the interest. However, after that, they could not afford to pay the extra 100 billion each year. If they had borrowed 400 billion to build 100 apartments, they could have sold them gradually in order to pay the interest. In this case, they built a hotel. They could not sell a few rooms or floors of the hotel to pay back the debt (Table 2).

According to a study (Han, 1992b), on average, it takes 20-30 years to recover investment capital for a resort or hotel project, if the investor only relies on incomes generated from resort or hotel services. In North America, when sponsoring long-term projects, investors normally rely on issuing bonds, which are 20-30 years valid. Meanwhile, in Vietnam, even Asia, this is a rare happening. Therefore, Asian SMEs suffer greater risks 
in managing cash flow and the 1997-1998 Asian financial crisis originated from this type of mistake (Seitz \& Ellison, 2005).

Table 2

Cash Flow of Canadeo Hotel (Billions VND)

\begin{tabular}{|c|c|c|c|c|c|c|c|c|c|c|}
\hline 1 & 2 & 3 & 4 & & 1 year & & & & & \\
\hline $\begin{array}{l}\text { Number of } \\
\text { Room }\end{array}$ & $\begin{array}{l}\text { Price } \\
\text { (VND/night) }\end{array}$ & $\begin{array}{l}\text { Capacity } \\
\text { of rent } \\
(\%)\end{array}$ & $\begin{array}{l}\text { Cost of } \\
\text { operation/ } \\
\text { Income }\end{array}$ & & $\begin{array}{l}\text { CF in per year } \\
(=1 \times 2 \times 3 \times 365)\end{array}$ & $40,880,000,000$ & VND & & & \\
\hline 100 & $1,400,000$ & $80 \%$ & $40 \%$ & & $\begin{array}{l}\text { CF out per year } \\
(=4 \times C F \text { in })\end{array}$ & $16,352,000,000$ & VND & & & \\
\hline Year & 1 & 2 & 3 & 4 & 5 & 6 & 7 & 8 & 9 & 10 \\
\hline CF out & -300 & -300 & -16.35 & -16.35 & -16.35 & -16.35 & -16.35 & -16.35 & -16.35 & -16.35 \\
\hline $\mathrm{CF}$ in & & & 40.88 & 40.88 & 40.88 & 40.88 & 40.88 & 40.88 & 40.88 & 40.88 \\
\hline CF project & -300 & -300 & 24.528 & 24.528 & 24.528 & 24.528 & 24.528 & 24.528 & 24.528 & 24.528 \\
\hline $\begin{array}{l}\text { CF of debt: } \\
\text { borrow \& } \\
\text { pay the } \\
\text { principal }\end{array}$ & 200 & 200 & & & -100 & -100 & -100 & -100 & & \\
\hline
\end{tabular}

\section{Solutions}

Unlike pre-feasibility studies for a new project which people have plenty of time to discuss or debate, company rescue plans are often prepared in a short period of time and under extremely difficult circumstances with the aim of convincing lender or banks that the company deserves a last chance to change and that such last chance is very feasible.

\section{Short-term Plan}

A short-term rescue plan must be drawn up urgently in order to restore debtors' trust, rekindle the company's hopes, and stabilize the situation temporarily.

A common problem is shortages of money or capital. Therefore, one of the first things that must be done is to minimize costs and at the same time, seek new sources of capital. Other things include cutting down on staff, reducing salaries or wages, selling unnecessary assets, collecting debts, re-sponsoring, and seeking new investors. This may sound very easy. However, when a company is in trouble, who can it sell its assets to? Even if it finds someone who wants to buy its assets, it can only sell them for very low prices. Borrowing or calling for investment is certainly no easy task. It is therefore very important that the company uses its creativity to find new ways of making money.

Vo Ta Han at Singapore in 1985 rescued successfully an ailing hotel from bankruptcy. A part of the Canadeo hotel's income was from its four restaurants. He came up with the idea of letting those who reserved their wedding dinners at the restaurant. After that, reservations came in thick and fast with some being made one year in advance. Seeing the deposits for the whole next year, the lender (Seabank) decided to cancel the bankruptcy of this SME and allow it to continue running.

For an initial short term when many problems must be dealt with simultaneously, it is advisable to choose a relatively easy way to handle problem and try to solve it completely before working on the others (Michael Corkery Condo Hotels, 2006). 


\section{Long-term Plans}

For its survival and development, a company must be in a trade that is on a faster track than others. Otherwise, it must outperform other companies in the same trade. A long-term plan needs to focus on four points as follows (Chin, 2007):

- Completely reviewing the company's operations, reducing costs, and increasing productivity;

- Evaluating the cash flow and the efficiency of all of the company's assets;

- Improving marketing and changing products;

- Reviewing the company's tactics.

After estimate cash flows of the Canadeo Hotel, authors came up with the advice: shifting the business model from renting out hotel rooms on a nightly basis to sell them as a condo hotel and get a lump sum.

A condo hotel, also known as a hotel-condo or a Contel, is a building, which is legally a form of housing tenure, but which is operated as a hotel, the investor, instead of hiring a hotel manager, will pay someone experienced in managing a condo hotel. A condo hotel works like any hotel that you know. The only difference is that each room of a condo hotel belongs to some individual.

Condo hotels are typically high-rise buildings developed and operated as luxury hotels, usually in major cities and resorts (Han, 2009). These hotels have condominium units which allow someone to own a full-service vacation home. When they are not using this home, they can leverage the marketing and management done by the hotel chain to rent and manage the condo unit as it would any other hotel room (Han, 2010).

As a guest of a hotel, you will have to pay for the services you get for the nights you stay. As an owner, you will only have to pay for the ownership of your room. Therefore, you own it publicly. This is similar to owning your current apartment. The difference is that your asset will be taken care of by a team of experienced managers who will be responsible for day-to-day operations of your room and for renting it out.

Typical owners of a condo hotel are divided into two main groups:

- Those who have an enjoyable way of life;

- Investors.

Those in the first group tend to buy or sell a condo hotel in their favorite places. They love the idea of owning some unimaginable accommodation in their favorite place, but they do not want to shoulder the burden of an empty second home, i.e.. one without furniture, which can make them financially exhausted. They are also attracted to the idea of having their holiday home managed, readily cleaned and tidied up by some professional before they arrive. In addition, they want to be compensated with the provided amenities and services. Such customers are those who are genuinely interested in a condotel and tend to spend their holidays there five or six times a year.

On the contrary, investors will buy a condotel regardless of whether it suits their lifestyles or not. What they need to know is whether such an asset is within their financial capabilities. To genuine investors, value addition and cash flow are extreme important and the first one seems to be more deciding. In addition, the opportunity to own an asset without having to worry about its maintenance, which is put in the hands of a professional management agency, is considered to be one of the factors that increase the value of the asset.

Investment in condotels is a quite common trend in the United States. In Vietnam, it is a good solution for managing the cash flow of resort or hotel projects, because the investor can collect a lump sum when they sell a 
condotel instead of collecting daily rents. In 2013, the Canadeo Hotel sold half of its rooms as condotels, thereby getting an amount of money large enough to pay its debts. By restructuring its products and services toward a condotel, the owner of the Canadeo Hotel managed to get sufficient money to pay both the interest and principal within eight years. As a result, it escaped the risk of going bankrupt and gradually established its reputation in condotel management and real estate finance.

The above short- and long-term plans are all theoretical (Rothschild's Global Financial Advisory Business, 2011). The next thing to do is to draw up an action plan and detailed cash flow estimation for the next 12 months and take action immediately. During this period, the company must tighten its belts and act closely in accordance with the estimated cash flow.

\section{Conclusions}

After drawing up rescue plans, what is important is to choose management, which does not only require one individual but also a whole team of dynamic, knowledgeable, capable, and experienced managers. The global and Vietnamese economies are struggling to get out of the financial crisis. The Vietnamese government has introduced incentives for SMEs. However, SMEs must design business plans and cash flow by themselves and innovate their management, so it keeps up with international practices and increases their competitiveness. By doing so, they can have an easier access to lenders and stakeholders, thereby maximizing their corporate value. Also, this paper is intended for private companies who want the financial institutions and banks come together to restructure the debt of companies facing financial difficulties, in order to provide timely support for such companies.

\section{Reference}

Chin, C. (2007). Helium report guide to Condo Hotels. Retrieved from https://en.wikipedia.org/wiki/Condo_hotel

Han, V. T. (1992a). The bankruptcy association. Journal of Saigon Time Economy, 3, 4-4.

Han, V. T. (1992b). Save a society. Journal of Saigon Time Economy, 4, 7-7.

Han, V. T. (2009). Letter from Singapore. Journal of Saigon Time Economy, 2, 8-8.

Han, V. T. (2010). Fundamentals of Investments. Journal of Saigon Time Economy, 7, 10-10.

Michael Corkery Condo Hotels. (2006). The latest twist in buying a vacation residence. Retrieved from https://en.wikipedia.org/wiki/Condo_hotel

Rothschild's Global Financial Advisory Business. (2011). Debt advisory and restructuring. Retrieved from https://www.rothschild.com/global_financial_advisory

Seitz, N. E., \& Ellison, M. (2005). Capital budgeting and long-term financing decisions. Mason: Thomson South-Western. 